\title{
Reseacch S Suare \\ Persistent Effect of Temperature on GDP Identified from Lower Frequency Temperature Variability
}

Bernardo Bastien-Olvera ( $\nabla$ bastien@ucdavis.edu )

University of California, Davis https://orcid.org/0000-0002-3734-4267

Frances Moore

University of California, Davis

Physical Sciences - Article

Keywords: temperature variability, climate, human wellfare

Posted Date: June 11th, 2021

DOI: https://doi.org/10.21203/rs.3.rs-601512/v1

License: (c) (i) This work is licensed under a Creative Commons Attribution 4.0 International License.

Read Full License 


\title{
Persistent Effect of Temperature on GDP Identified from Lower Frequency Temperature Variability
}

\author{
Bernardo Bastien-Olvera ${ }^{1}$ and Frances C. Moore ${ }^{2}$
}

\begin{abstract}
It is well established that temperature variability affects a range of outcomes relevant to human welfare, including health (Gasparrini et al., 2017) emotion and mood (Baylis et al., 2018), and productivity across a number of economic sectors (Carleton \& Hsiang, 2016; Dell et al., 2014). However, a critical and still unresolved empirical question is whether temperature variation has a long-lasting effect on economic productivity and, therefore, whether damages compound over time in response to long-lived changes in temperature expected with climate change. Several studies have identified a relationship between temperature and GDP (Burke et al., 2015; Dell et al., 2012; Kalkuhl \& Wenz, 2020), but empirical evidence as to the persistence of these effects is still weak. This paper presents a novel approach to isolate the persistent component of temperature effects on output using lower frequency temperature variation. Using three different datasets we find that longer temperature anomalies affect GDP growth as much or more than short-lived anomalies, implying persistent and therefore cumulative effects of climate change on economic output. The population-weighted global effect of -0.8 pp per degree is sufficient to reduce per-capita income in 2100 by $44 \%$ under RCP6, approximately an order of magnitude larger than damages currently represented in cost-benefit integrated assessment models (Diaz \& Moore, 2017).
\end{abstract}

A large body of evidence now exists showing a relationship between temperature fluctuations and economic productivity. Temperature has been shown to influence output at global (Burke et al., 2015; Dell et al., 2012), national (Deryugina \& Hsiang, 2017; Schlenker \& Roberts, 2009), and regional scales (Kalkuhl \& Wenz, 2020), affecting a wide range of sectors in both rich and poor countries. The persistence of these impacts has first-order implications for the magnitude of climate change damages: if temperature fluctuations affect the determinants of economic growth then they have a persistent impact on the level of economic output. In this case climate change damages are cumulative and may be orders of magnitude larger than currently represented in models used for the cost-benefit analysis of climate change, which mostly assume non-persistent damages (Dietz \& Stern, 2015; Moore \& Diaz, 2015; Moyer et al., 2014).

Despite its importance for determining the aggregate costs of climate change, evidence on the persistence of the impacts of temperature shocks is sparse and contradictory. Dell, Jones and Olken (2012) show that non-persistent impacts to output and persistent impacts to growth can produce identical

\footnotetext{
${ }^{1}$ Geography Graduate Group, University of California Davis

${ }^{2}$ Department of Environmental Science and Policy, University of California Davis
} 
contemporaneous effects, but can be distinguished using lagged temperature effects. Using global national accounts data, they fit a reduced-form model with lagged temperature terms and find evidence that effects of temperature shocks in poorer countries persist for at least 10 years, implying large negative effects of higher temperatures for economic growth, at least in the medium-term. Using a similar dataset, Burke, Hsiang and Miguel (2015) find robust evidence for a non-linear, hill-shaped relationship between contemporaneous temperature and GDP growth, but evidence for persistent impacts to the economy is weaker since the sum of lagged effects has large standard errors with confidence intervals that overlap zero. In a model-selection exercise based on cross-validation, Newell, Prest and Sexton (2020) show total climate damages are highly sensitive to the question of persistence, and to the functional form of empirical models used to estimate effects. At a smaller spatial scale, Deryugina \& Hsiang (2017) found evidence of persistent but declining effects during the first 10 years after a temperature shock in individual U.S. counties, and Colacito et al. (2019) found that increases in summer and fall temperature could have persistent effects on gross state product of U.S. states.

A major empirical challenge is that estimating the sum of lagged effects, particularly for a non-linear function, can produce large standard errors and therefore high uncertainty. For instance, in the quadratic specification used by Burke, Hsiang and Miguel (2015), identifying cumulative effects over 10 years requires estimating and summing 20 regression coefficients. The uncertainty in this statistic depends on the variance and covariance of all 20 parameter estimates. More recent empirical investigations of climate impacts on economic growth have focused on resolving detail at the subnational scale (Colacito et al., 2018; Damania et al., 2020; Kalkuhl \& Wenz, 2020), or on resolving impacts on the production process (Letta \& Tol, 2019). While these suggest some persistence in temperature effects, this key question relevant for understanding the aggregate costs of climate change remains largely unresolved.

\section{Approach}

Here we propose a statistical test to differentiate between persistent effects of temperature on growth and temporary effects of temperature on output using lower-frequency temperature variation. We first use a simulation exercise to demonstrate the discriminatory power of the test. Second, we implement this test on individual country-level time-series of temperature and economic growth, and finally and characterize the aggregate evidence for growth vs levels effects.

The essence of the approach is that persistent and transient impacts to economic output can be distinguished using temperature variation occurring at different frequencies. Internal variability of the 
climate system gives rise to oscillations at different timescales. This is an intrinsic characteristic of nonlinear dynamic systems like the Earth's climate (Lorenz, 1963). While some of these fluctuations such as the El Nino Southern Oscillation with a period of 2 to 7 years are well understood (e.g. Imbers et al., 2013), spectral analysis of atmospheric time series reveal fluctuations at all possible frequencies (Hasselmann, 1976; Mann et al., 2020) Figure 1a shows this variability in the US temperature time series between 1960 and 2017 (Matsuura \& Willmott, 2018a, 2018b). We use a low-pass filter to successively remove highfrequency variation and obtain temperature time series that preserve only lower-frequency oscillations.

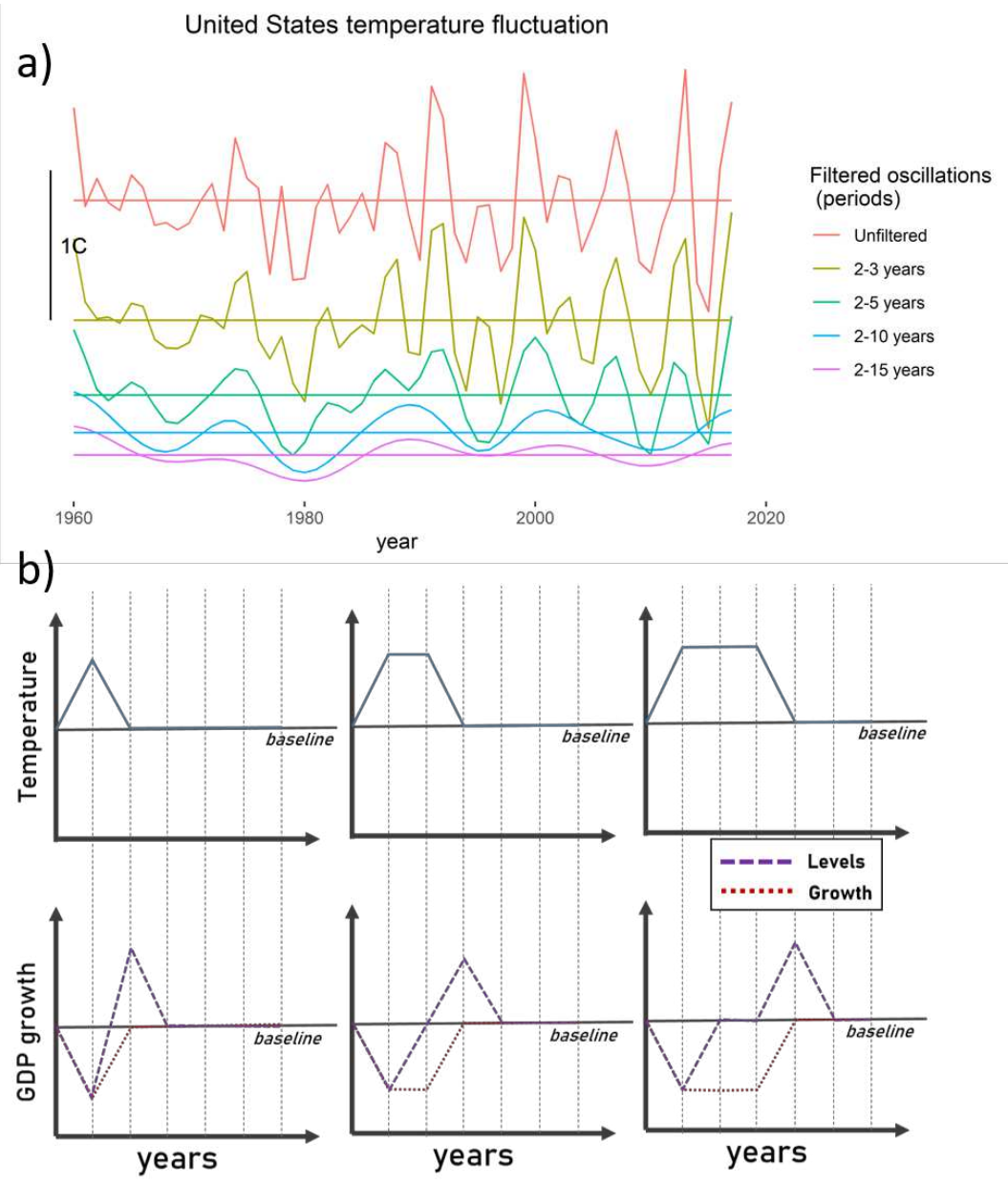

Fig 1. Temperature fluctuations and its effects at different frequencies. a) US population-weighted temperature fluctuations after detrending and filtering higher-frequency variation (Matsuura \& Willmott, 2018a). The top, orange line shows the US temperature time series. Lower lines show the filtered time series, removing successively more higher-frequency variation. We spread the time-series across y-axis for visual purposes only but in reality all time-series oscillate around zero because they were demeaned and de-trended before filtering.

b) Temperature shocks at decreasing frequencies are shown in the upper panels while the effects of those shocks on GDP growth, under both the levels and growth models, are given in the lower panels. 
Temperature variability at different timescales would be expected to produce distinct economic dynamics depending on the persistence of economic impacts. This is illustrated in Figure $1 \mathrm{~b}$, which shows the change in GDP growth that would be expected under temperature shocks of different durations and alternate models of economic impact. Dell et al. (2012) derive a simple equation for a model that includes both non-persistent levels impacts $(\beta)$ and persistent growth impacts $(\gamma)$, given baseline growth rate g:

$$
g_{t}=g+(\beta+\gamma) T_{t}-\beta T_{t-1}
$$

Where $T_{t}$ is the deviation in temperature from some mean value in period $t$. Figure $1 \mathrm{~b}$ illustrates how the timescale of temperature variation interacts with the models of economic impact, using two extreme cases. In the "levels model" we set the growth effect to zero (i.e. $\gamma=0$ ) so that:

$$
g_{t}=g+\beta\left(T_{t}-T_{t-1}\right)=g+\beta \Delta T_{t}
$$

In the "growth model", we set the level effect to zero (i.e. $\beta=0$ ) so that:

$$
g_{t}=g+\gamma T_{t}
$$

For one period temperature shocks, the contemporaneous effect of temperature on economic growth is the same under the two scenarios (Figure 1b, left panel). However, for longer temperature excursions, there are time periods where $\Delta T_{t}=0$ but $T_{t}>0$, causing the two impact models to produce divergent predictions. In particular, effects on growth continue under long temperature excursions, whereas initial effects in the levels model subsequently attenuate to zero (Figure $1 \mathrm{~b}$, right panel).

This means that it should be possible, in principle, to distinguish these two cases in empirical data using different timescales of temperature variability. It is a common practice in signal processing problems to decompose time series into a sum of periodic components with varying frequencies, amplitudes and phases (Duhamel \& Vetterli, 1990), widely used in a variety of fields like audio processing, electrical engineering, and climate science (Bergland, 1969; Ghil, 2002; Smith, 2007). This approach allows the timeseries to be reconstructed using a specific subsets of desired frequencies. A low-pass filter is a version of the time series that only preserves low frequency components. Following studies in the climate literature (e.g. Mann et al., 2014), we use a low-pass filter to remove inter-annual variations and obtain temperature 
time series that preserve only lower-frequency oscillations. If temperature shocks affect output but not the underlying growth rate, the estimated effect using only longer period temperature changes on GDP growth, should be smaller than that estimated using the unfiltered time series. In contrast, if temperature shocks have a persistent effect on growth, then the estimated effect will not vary with the frequency of temperature variation used for estimation.

Figure 2 demonstrates this effect in a simulation exercise. This shows results from time series regressions of simulated economic growth on simulated temperature at different levels of filtering under two cases one in which temperature affects only the level of output (purple line) and one in which it affects the growth rate (pink line). The random temperature time series used in the simulations preserve the frequency distribution of the Earth's natural oscillations by matching the spectral decomposition on 1500 years of pre-industrial global temperatures based on the Last Millennium Reanalysis (Tardif et al., 2019). Using this decomposition we generate 10,000 random 350 year temperature time-series that preserve this frequency distribution but with random phase shifts (e.g. Figwer, 1997) and then simulate economic dynamics for each temperature time series under the two alternate impacts models, using equations 2 and 3 and adding an independent and identical distributed (iid) noise component. We regress the simulated economic growth data on temperature after filtering out varying ranges of frequencies from the temperature time series.

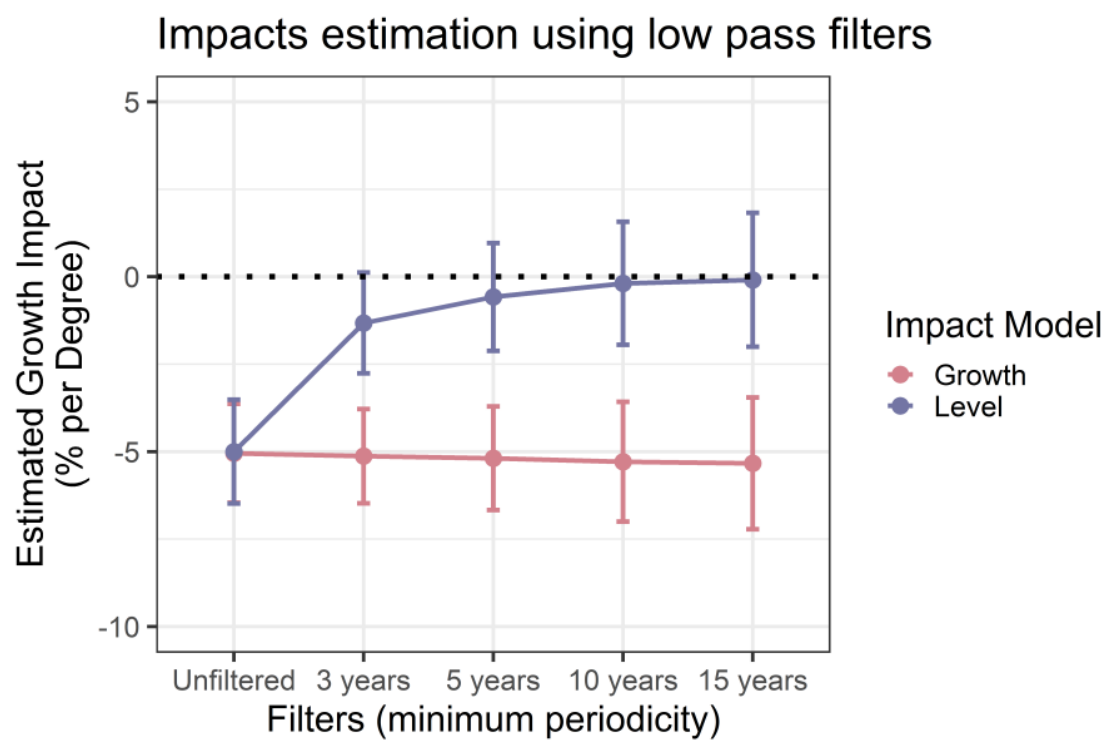

Figure 2. Simulation exercise demonstrating the divergence of regression results under increasing frequency filters under two alternate models of temperature impacts on economic production, a non-persistent "levels" model (purple) and a fully persistent "growth" model (pink). 
Figure 2 shows the mean value of the estimated coefficients and its standard error for all the simulations. Without any filtering using only contemporaneous temperatures, the two types of impacts are indistinguishable, as originally pointed out by Dell, Jones and Olken (Dell et al., 2012). But filtering out high frequencies in the temperature data produces divergent effects: the estimated effect under growth impacts remains constant while the coefficients in the levels case attenuate markedly. In other words, the divergence of the pink and purple lines in Figure 2 at lower frequencies, means that these two possible worlds - one with and one without persistent temperature impacts - could potentially be distinguished using this method.

The general approach of using lower frequency temperature variation to better understand the magnitude and dynamics of climate change impacts is well established in the climate impacts literature. Several papers contrast impacts estimated using high-frequency weather variation with those estimated using lower-frequency variation, either average temperature differences over long intervals (i.e. "long differences") or multi-decadal moving averages, to identify the effects of adaptation on the levels of climate damages (Burke \& Emerick, 2016; Kolstad \& Moore, 2020; Mérel \& Gammans, 2021; Taraz, 2017). Most notably, Hsiang (2016) presents panel regressions of US temperature and corn yield data, successively filtering out higher-frequency temperature and yield variation and argues that the stability of regression estimates using longer temperature variation indicates agricultural adaptation to warming is either slow or ineffective.

While conceptually similar to our empirical approach, the question this literature addresses is distinct in that, because the dependent variable in each case is a level outcome (typically crop yields), these papers address how adaptation does or does not attenuate the level of climate damages as a function of the longevity of temperature variation. Since our dependent variable is a growth rate, the question addressed is whether the effect of short-term temperature shocks on the level of GDP persist, and therefore whether damages compound over time in response to sustained periods of warming. Most importantly, even if the estimated growth effect attenuates to zero at lower frequencies (i.e. the purple line in Figure 2), this is still consistent with an effect of long-term warming on the level of GDP, for instance as modeled in the damage function of most cost-benefit integrated assessment models (Diaz \& Moore, 2017).

We use our test to investigate the persistence of temperature effects on economic production. We use GDP data from the World Bank covering 217 countries from 1961 to the present (World Bank, 2021), merging this dataset with population-weighted temperature and rainfall data from University of Delaware 
(Matsuura \& Willmott, 2018a, 2018b). To identify whether country-level temperature impacts have persistent effects we performed the following regression for each country:

$$
g_{t}=\theta_{f} T_{t, f}+\pi_{f} P_{t, f}+\epsilon_{t}
$$

Where $T_{t, f}$ and $P_{t, f}$ are the population-weighted temperature and rainfall in year $\mathrm{t}$ after filtering out frequencies lower than $\mathrm{f}$. The filters $f$ are low-pass filters that filter-out any oscillations with periods shorter than $3,5,10$, and 15 years, or $\mathrm{f}=$ =unfiltered when no filter was applied. The low-pass filter algorithm requires data that spans at least twice the upper bound periodicity, which results in some countries not having estimates for all the levels of filtering due to missing data at earlier time periods. Growth, temperature and rainfall data are all demeaned and detrended at the country-level prior to analysis.

\section{Results}

The behavior of the estimates $\theta_{f}$ for each country contains information about the persistence of temperature effects on the economy. Figure 3 shows the estimated values of $\theta_{f}$ for all countries at different levels of filters, binned into three broad categories: an intensifying effect, where the absolute value of $\theta_{f}$ increases at lower frequencies (left panel); a constant effect over different frequency filters (central panel); and a converging effect, where the absolute value of $\theta_{f}$ decreases at lower frequencies (right panel). We find that a large majority of countries (153 out of 176 where we found an estimate) have intensifying or constant effects using lower frequency temperature variability, consistent with a persistent effect of temperature on output, at least in the medium term (up to 15 years). 42 countries have lowerfrequency estimates that are statistically different from zero at the $90 \%$ confidence level (of which 18 might be expected as false positives given the number of comparisons).

The majority of countries (117), show evidence for intensifying effects at lower frequencies, where the effect of each degree of warming becomes larger for longer temperature excursions. An intensifying effect might be due to adjustment dynamics whereby people and firms are able to better exploit beneficial opportunities (for positive effects) or gradually exhaust limited coping resources (for negative effects) in the face of longer-term temperature fluctuations. Another explanation would be if countries experience a combination of level and growth effects with opposite signs that partially offset each other in the unfiltered estimate, a pattern identified by Dell, Jones and Olken (2012) for some countries. A final explanation for this intensifying pattern is statistical: substantial measurement error in the temperature variable could attenuate the estimated coefficient, biasing it towards zero. Applying filters will gradually 
filter out noise in the temperature variable, producing larger coefficients closer to the true growth effect. A second simulation exercise demonstrates this effect but also shows the levels and growth cases to be distinguishable, even in the presence of measurement error (Supplementary Figure 1).

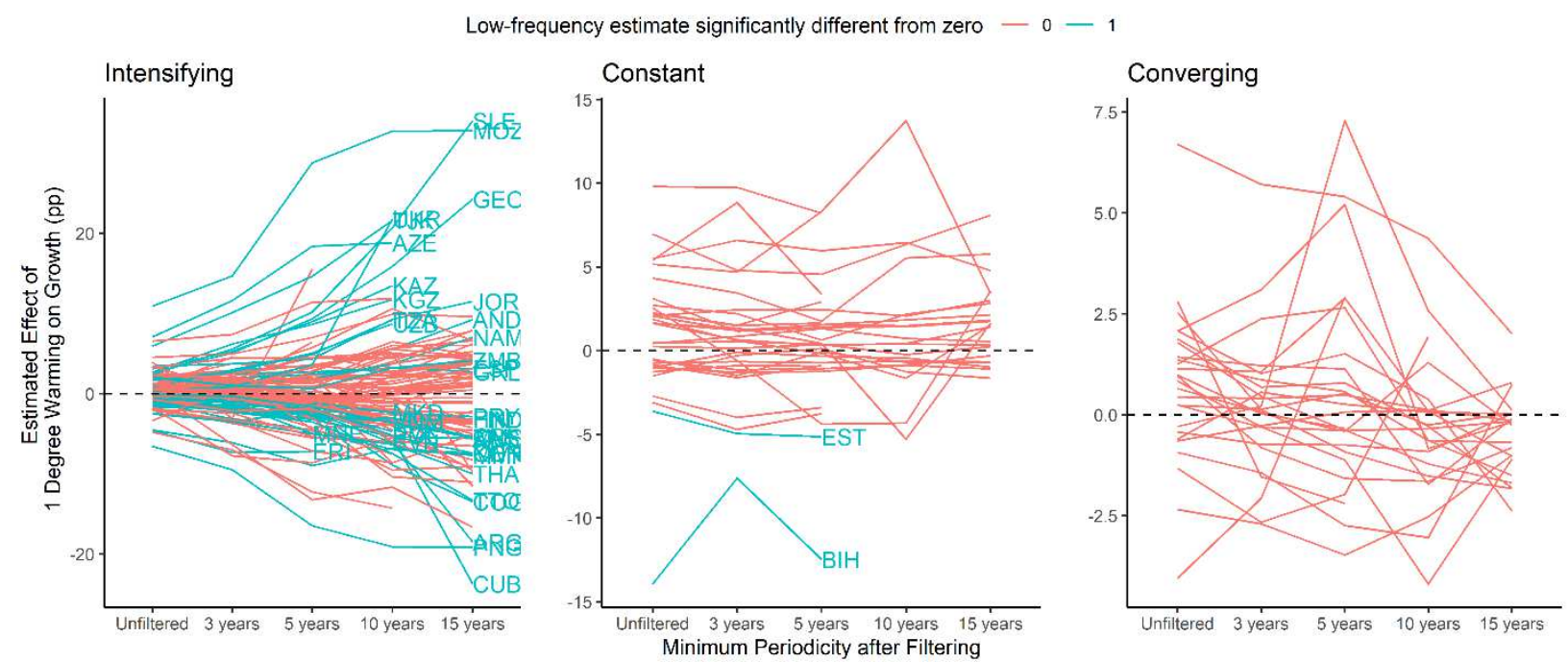

Fig 3. Country-level estimates of temperature effect on economic growth. Left panel: Those countries for which the absolute value of the lower-frequency estimate is 1.5 times larger than the magnitude of their unfiltered estimate. Middle panel: Those countries which low-frequency estimate does not diverge from the unfiltered estimate (criterion: low-frequency estimate within unfiltered estimate +/- half the raw estimate value). Right panel: All remaining countries.

We performed the same analysis using two alternative economic growth datasets that span a longer time period but include fewer countries. Firstly we used the Barro-Ursua dataset, with annual data on economic growth of 43 countries starting as early as 1790 to 2009 , developed to examine the persistence of macroeconomic shocks (Barro \& Ursúa, 2008; Barro \& Ursua, 2010). Secondly, we use the Maddison Project database that standardizes country-level GDP per capita for 170 countries, some of them back to the beginning of the Common Era, to 2018 (Bolt \& van Zanden, 2020). Due to the sparsity of temperature and rainfall records pre-1900, we use only post-1900 data for both datasets. Supplementary Figure 2 replicates Figure 3 for these two alternate datasets covering different subsets of countries and much longer timeperiods than the World Bank data. We again see evidence that most countries show constant or intensifying effects of temperature at lower frequency variability, rather than the converging coefficients associated with a levels effect of temperature on GDP. 
We analyze the evidence for persistence across all countries at the global scale by pooling the estimate shown in Figure 3 and estimating the following regression model

$$
\left|\theta_{f, c}\right|=F_{f}+\epsilon_{f, c}
$$

Where the absolute value of the temperature coefficient estimate in country $\mathrm{c}$ at filtering level $\mathrm{f}\left|\theta_{f, c}\right|$ is regressed on the level of filtering $F$, clustering standard errors at the continent level. If a nonpersistent, levels effect were dominant, we would expect to see the absolute magnitudes of the filtered estimates converging towards zero, indicating a negative coefficient estimate on the filtering variables F. Table 1 shows the results of this regression model, and shows that, across all countries, we do not see evidence for this attenuating effect. Instead, like Figure 3, the regression results show evidence for an intensifying effect where the absolute value estimated using lower frequency temperature variation is larger than the value estimated using unfiltered data, as indicated by positive coefficients on the filtering variables in Table 1.

Supplementary Figure 3 examines whether the direction and persistence of temperature impacts is associated with either per capita GDP or mean temperature. We find no systematic differences in the estimated long-term temperature effect between rich and poor or cold and hot countries.

Figure 3 shows both positive and negative effects of warming in different countries, but the average global effect, weighting by both GDP and population, is negative. For short-term impacts, the combination of levels and growth effects has a population-weighted mean value of -0.007 percentage points (pp) per degree of warming, which intensifies to -0.8 pp per degree of warming, using the lowest frequency estimate.

\section{Discussion}

Here we show evidence that temperature shocks have historically had persistent effects on economic output across a broad range of countries. The question of the persistence of climate damages is a first order problem for climate change economics. Studies that model climate impacts on economic growth, tend to produce aggregate climate change cost an order of magnitude larger than studies modeling only levels impacts (Moore \& Diaz, 2015; Ricke et al., 2018). This is because, in response to the permanent shifts in temperature expected with climate change, persistent impacts compound over 
time, producing far larger aggregate damages over the long time-frames relevant for assessing climate change costs.

Dependent variable:

\begin{tabular}{cccccc}
\hline \multicolumn{5}{c}{ Absolute value of temperature coefficient } \\
$(1)$ & $(2)$ & $(3)$ & $(4)$ & $(5)$ & $(6)$ \\
\hline $0.022^{* * *}$ & $0.013^{* * *}$ & $0.014^{* * *}$ & $0.010^{* * *}$ & $0.020^{* * *}$ & $0.013^{* * *}$ \\
$(0.005)$ & $(0.003)$ & $(0.004)$ & $(0.003)$ & $(0.004)$ & $(0.003)$ \\
0.003 & $0.003^{* * *}$ & $0.002^{* * *}$ & $0.002^{* * *}$ & $0.004^{* *}$ & 0.002 \\
$(0.002)$ & $(0.001)$ & $(0.0005)$ & $(0.0004)$ & $(0.002)$ & $(0.001)$ \\
$0.012^{* * *}$ & $0.009^{* * *}$ & $0.003^{*}$ & $0.004^{* * *}$ & $0.010^{* * *}$ & $0.006^{*}$ \\
$(0.004)$ & $(0.003)$ & $(0.001)$ & $(0.001)$ & $(0.004)$ & $(0.003)$ \\
$0.025^{* * *}$ & $0.019^{* * *}$ & $0.008^{* * *}$ & $0.007^{* * *}$ & $0.026^{* * *}$ & $0.016^{* * *}$ \\
$(0.005)$ & $(0.005)$ & $(0.002)$ & $(0.002)$ & $(0.006)$ & $(0.005)$ \\
$0.031^{* * *}$ & $0.020^{* * *}$ & $0.011^{* *}$ & $0.008^{* *}$ & $0.027^{* * *}$ & $0.018^{* * *}$ \\
$(0.006)$ & $(0.005)$ & $(0.004)$ & $(0.003)$ & $(0.005)$ & $(0.004)$ \\
& & & & & \\
World Bank & World Bank & Barro & Barro & Maddison & Maddison \\
814 & 814 & 205 & 205 & 780 & 780 \\
0.049 & 0.073 & 0.040 & 0.034 & 0.069 & 0.063 \\
0.044 & 0.068 & 0.021 & 0.015 & 0.064 & 0.058 \\
0.052 & 0.195 & 0.020 & 0.125 & 0.041 & 0.196 \\
None & Inverse SE & None & Inverse SE & None & Inverse SE \\
217 & 217 & 43 & 43 & 170 & 170 \\
$1961-2020$ & $1961-2020$ & $1900-2009$ & $1900-2009$ & $1900-2018$ & $1900-2018$ \\
\hline \multicolumn{7}{c}{ (1) } & & & & ${ }^{*} \mathrm{p}<0.1 ;^{* *} \mathrm{p}<0.05 ;^{* * *} \mathrm{p}<0.01$
\end{tabular}

Table 1. Results of regression model. Standard errors clustered at the continent level. Model 1 is unweighted, and Model 2 weights by the inverse of the standard deviation of the parameter $\theta_{f, c}$, the value of the estimated temperature coefficient at filter $\mathrm{f}$ in country $\mathrm{c}$.

In contrast with previous literature that has mostly used high-frequency, year-to-year temperature variation to estimate climate impacts on the economy, here we use lower frequency variation. Our identification strategy focuses on the persistent effect of temperature by controlling for time-trends and country-specific dynamics (via demeaning and detrending) but uses multi-year temperature variability instead of lags to distinguish between growth and levels effects. 
Applying this test to three different datasets of economic growth, we fail to find strong evidence of declining temperature effects at longer time horizons. For most countries, the estimated effects of temperature on the economy do not attenuate after filtering out high frequencies, and in many countries they instead intensify over time. Specifically, we found persistent temperature impacts on economic growth in $85 \%$ (68\%; $87 \%$ ) of the countries, out of which more than $78 \%$ (75\%; $83 \%)$ have an estimate that intensifies in the medium-run using the World Bank (Barro-Ursua; Maddison Project) dataset. This intensifying dynamic might be due to adaptation or coping dynamics, changing effects of measurement error (See Supplementary Figure 1), or competing growth and levels effects with different signs. Whatever the explanation, the identification of effects that are both economically meaningful and, in some cases, statistically different from zero using only lower frequency temperature variation suggests a sensitivity of aggregate economic output to temperature shocks that persists over at least the 5-15 year time frame.

Like previous work, we find both positive and negative effects of temperature on different countries. Aggregating to the global level, we find net negative effects on both the average person (weighting by population) and the average dollar (weighting by GDP), with lowest-frequency estimates of -0.8 and -1.5 percentage point reduction in growth per degree of warming, respectively. This has large economic implications, for instance, the Shared Socioeconomic Pathway 2 (a middle-of-the-road scenario) projects that global income in 2100 will more than quadruple with respect to 2020, with an annual equivalent growth rate of $2 \%$. Given temperature projections under RCP6, our aggregate population-weighted estimate suggests incomes in 2100 would be $43 \%$ lower with annual average income growth cut to $1.2 \%$. For comparison, damages at a similar level of warming using damage functions in the three main integrated assessment models used to calculate the social cost of carbon are an order of magnitude smaller (Diaz \& Moore, 2017).

While providing evidence of persistent impacts of temperature shocks on growth, our framework does not isolate the mechanisms by which they arise. Past studies have modeled persistent impacts as resulting from a slow-down in total factor productivity growth (Moore \& Diaz, 2015; Moyer et al., 2014), changes to the capital depreciation rate (Moore \& Diaz, 2015), or impacts to the stock of natural capital (BastienOlvera \& Moore, 2021). Other studies leave the mechanism of growth rate impacts unspecified (Glanemann et al., 2020; Ricke et al., 2018). Letta \& Tol (2019) investigate this question and suggest impacts arise through effects on total factor productivity growth, but more work is needed to understand exactly how these impacts manifest. Our findings show that in the long-term societies are sensitive to 
changes in climate and that the risk associated with climate change could be greatly underestimated if we overlook the persistent nature of impacts.

\section{Methods}

For the simulation exercise (Figure 2), we first generated 10,000 random 350-year temperature time series that preserve the internal dynamics and characteristic periodicity intrinsic to the climate system. This dynamic was retrieved by performing a fast Fourier transform (FFT) of 1500 years of global mean surface temperature data prior to anthropogenic influence, obtained from the Last Millennium Reanalysis project (Tardif et al., 2019). Simulated temperature time-series were generated using the spectral profile given by this FFT but with randomly chosen phases, generating 10,000 random counterfactual time series that might have arisen from the Earth's natural variability.

For each of the 10,000 temperature time series we generated two alternative economic growth time series that reflected the two climate impacts scenarios that we hope to distinguish: levels and growth. Following Dell et al. (2012), the levels model is given by $g_{t}=g+\beta T_{t}-\beta T_{t-1}$ and the growth model by $g_{t}=g+\gamma T_{t}$. The growth baseline $g$ was set at 0.01 representing $1 \%$ per year baseline growth, the temperature coefficients $\beta$ and $\gamma$ were both set at -0.05 representing $5 \%$ decrease in growth per degree of warming, and a random noise was drawn from a normal distribution with standard deviation of 0.005 , representing growth rate variability unexplained by temperature.

The persistence test consists of regressing growth on temperature after filtering the temperature time series to remove higher frequency oscillations. We use a low-pass filter in R (pass.filt from dplR library) that removes all oscillations with periodicity between 2 and the desired upper boundary of the filter. We perform the regressions of simulated growth on simulated temperature for 4 sets of filters (upper boundary $=3,5,10$ and 15 ), and an unfiltered case. The unfiltered case, in both the simulations and the main regressions also includes a one-year temperature lag. This is required for generating an unbiased estimate of the levels effect - if temperature affects levels then $T_{t-1}$ determines $g_{t}$ (i.e. equation 2). Omitting $T_{t-1}$ will therefore bias estimates of the effect of contemporaneous temperature shocks $\left(T_{t}\right)$ if there is temporal autocorrelation in the timeseries. Lags are not included in regressions using filtered temperature data since these regressions are intended to integrate the effect of persistent temperature excursions. Figure 2 shows the mean value of the estimates after filtering the temperature data and the 95\% confidence interval. 
We retrieved yearly country-level data on economic growth for the 217 countries in the World Bank database (World Bank, 2021) for the period 1960 to 2020. Gridded temperature and precipitation data from the University of Delaware dataset (1900 to 2017;Matsuura \& Willmott, 2018a, 2018b) was aggregated to the country level using 2015 population weighting from the Gridded Population of the World version 4 dataset (Doxsey-Whitfield et al., 2015). Alternative datasets that were used to check for the robustness of the results (See Supplementary Figure 2) were: 1) the Barro-Ursua economic dataset that covers 43 countries from the late $18^{\text {th }}$ century to 2009 (Barro \& Ursua, 2010), and 2) the Maddison Project economic dataset that covers a few countries starting in the $14^{\text {th }}$ century, a dozen or so countries starting in the late $18^{\text {th }}$ century, and more than 100 countries from 1950 to 2018 (Bolt \& van Zanden, 2020). Although these economic growth datasets go back further, we limit analysis to the post-1900 period because of temperature and rainfall data availability.

Temperature, rainfall and economic growth data was demeaned and detrended by country to remove time-invariant country variation and long-term, country-specific weather and growth rate trends. The residuals after demeaning and detrending were used to estimate the temperature effect $(\theta)$ on economic growth by performing the following regression for each country: $g_{t}=\theta_{f} T_{t, f}+\pi_{f} P_{t, f}+\epsilon_{t}$ where the index $(f)$ represents the level of filtering applied to the temperature and rainfall data before performing the regressions.

As shown by our simulation (Figure 2), the persistence test consists of identifying whether $(\theta)$ converges to zero after filtering higher frequencies. To characterize the behavior of $\theta$ we create three categories. The first category ("Intensifying") consists of those countries which absolute value of the estimate $\theta$ for the lowest frequency estimate is at least $50 \%$ larger than the absolute value of the estimate without filtering (i.e. $\left|\theta_{f=x}\right| \geq 1.5 *\left|\theta_{\text {unfiltered }}\right|$ where $x$ is the highest level of filtering available for that country). The second category ("Constant") are countries in which the estimate remains constant $(0.5 *$ $\left.\theta_{\text {unfiltered }} \geq \theta_{f=x} \geq 1.5 * \theta_{\text {unfiltered }}\right)$. The third category consists of the remaining countries, which estimate could be seen as converging to zero or even changing sign but without really having a significant long-term effect.

Estimates of future damages were computed using the average value of the global mean surface temperature projected by the models part of the Climate Model Inter-comparison Project 5 (Taylor et al., 2012), and the Shared Socioeconomic Pathway 2 base quantification (Fujimori et al., 2017). 


\section{References}

Barro, R. J., \& Ursúa, J. F. (2008). Macroeconomic crises since 1870. National Bureau of Economic Research.

Barro, R., \& Ursua, J. (2010). Barro-Ursua Macroeconomic Data. https://scholar.harvard.edu/barro/publications/barro-ursua-macroeconomic-data

Bastien-Olvera, B. A., \& Moore, F. C. (2021). Use and non-use value of nature and the social cost of carbon. Nature Sustainability, 4(2), 101-108.

Baylis, P., Obradovich, N., Kryvasheyeu, Y., Chen, H., Coviello, L., Moro, E., Cebrian, M., \& Fowler, J. H. (2018). Weather impacts expressed sentiment. PloS One, 13(4), e0195750.

Bergland, G. (1969). Fast Fourier transform hardware implementations-An overview. IEEE Transactions on Audio and Electroacoustics, 17(2), 104-108. https://doi.org/10.1109/TAU.1969.1162041

Bolt, J., \& van Zanden, J. L. (2020). Maddison style estimates of the evolution of the world economy. A new 2020 update. 44.

Burke, M., \& Emerick, K. (2016). Adaptation to climate change: Evidence from US agriculture. American Economic Journal: Economic Policy, 8(3), 106-140.

Burke, M., Hsiang, S. M., \& Miguel, E. (2015). Global non-linear effect of temperature on economic production. Nature, 527, 235-239. https://doi.org/10.1038/nature15725

Carleton, T. A., \& Hsiang, S. M. (2016). Social and economic impacts of climate. Science, 353(6304).

Colacito, Ric, Hoffmann, B., \& Phan, T. (2018). Temperatures and Growth: A Panel Analysis of the United States (SSRN Scholarly Paper ID 2546456). Social Science Research Network. https://doi.org/10.2139/ssrn.2546456

Colacito, Riccardo, Hoffmann, B., \& Phan, T. (2019). Temperature and growth: A panel analysis of the United States. Journal of Money, Credit and Banking, 51(2-3), 313-368. 
Damania, R., Desbureaux, S., \& Zaveri, E. (2020). Does rainfall matter for economic growth? Evidence from global sub-national data (1990-2014). Journal of Environmental Economics and Management, 102335.

Dell, M., Jones, B. F., \& Olken, B. A. (2012). Temperature Shocks and Economic Growth: Evidence from the Last Half Century. American Economic Journal: Macroeconomics, 4(3), 66-95.

Dell, M., Jones, B. F., \& Olken, B. A. (2014). What do we learn from the weather? The new climateeconomy literature. Journal of Economic Literature, 52(3), 740-798.

Deryugina, T., \& Hsiang, S. (2017). The Marginal Product of Climate (No. w24072; p. w24072). National Bureau of Economic Research. https://doi.org/10.3386/w24072

Diaz, D., \& Moore, F. (2017). Quantifying the economic risks of climate change. Nature Climate Change, 7(11), 774-782.

Dietz, S., \& Stern, N. (2015). Endogenous Growth, Convexity of Damage and Climate Risk: How Nordhaus' Framework Supports Deep Cuts in Carbon Emissions. The Economic Journal, 125(583), 574-620. https://doi.org/10.1111/ecoj.12188

Doxsey-Whitfield, E., MacManus, K., Adamo, S. B., Pistolesi, L., Squires, J., Borkovska, O., \& Baptista, S. R. (2015). Taking advantage of the improved availability of census data: A first look at the gridded population of the world, version 4. Papers in Applied Geography, 1(3), 226-234.

Duhamel, P., \& Vetterli, M. (1990). Fast fourier transforms: A tutorial review and a state of the art. Signal Processing, 19(4), 259-299. https://doi.org/10.1016/0165-1684(90)90158-U

Figwer, J. (1997). A new method of random time-series simulation. Simulation Practice and Theory, 5(3), 217-234. https://doi.org/10.1016/S0928-4869(96)00007-9

Fujimori, S., Hasegawa, T., Masui, T., Takahashi, K., Herran, D. S., Dai, H., Hijioka, Y., \& Kainuma, M. (2017). SSP3: AIM implementation of shared socioeconomic pathways. Global Environmental Change, 42, 268-283. 
Gasparrini, A., Guo, Y., Sera, F., Vicedo-Cabrera, A. M., Huber, V., Tong, S., Coelho, M. de S. Z. S., Saldiva, P. H. N., Lavigne, E., \& Correa, P. M. (2017). Projections of temperature-related excess mortality under climate change scenarios. The Lancet Planetary Health, 1(9), e360-e367.

Ghil, M. (2002). Advanced spectral methods for climatic time series. Reviews of Geophysics, 40(1), 1003. https://doi.org/10.1029/2000RG000092

Glanemann, N., Willner, S. N., \& Levermann, A. (2020). Paris Climate Agreement passes the cost-benefit test. Nature Communications, 11(1), 110. https://doi.org/10.1038/s41467-019-13961-1

Hasselmann, K. (1976). Stochastic climate models Part I. Theory. Tellus, 28(6), 473-485. https://doi.org/10.1111/j.2153-3490.1976.tb00696.x

Hsiang, S. (2016). Climate econometrics. Annual Review of Resource Economics, 8, 43-75.

Imbers, J., Lopez, A., Huntingford, C., \& Allen, M. R. (2013). Testing the robustness of the anthropogenic climate change detection statements using different empirical models. Journal of Geophysical Research: Atmospheres, 118(8), 3192-3199. https://doi.org/10.1002/jgrd.50296

Kalkuhl, M., \& Wenz, L. (2020). The impact of climate conditions on economic production. Evidence from a global panel of regions. Journal of Environmental Economics and Management, 103, 102360. https://doi.org/10.1016/j.jeem.2020.102360

Kolstad, C. D., \& Moore, F. C. (2020). Estimating the economic impacts of climate change using weather observations. Review of Environmental Economics and Policy, 14(1), 1-24.

Letta, M., \& Tol, R. S. J. (2019). Weather, Climate and Total Factor Productivity. Environmental and Resource Economics, 73(1), 283-305. https://doi.org/10.1007/s10640-018-0262-8

Lorenz, E. N. (1963). Deterministic Nonperiodic Flow. Journal of the Atmospheric Sciences, 20(2), 130141. https://doi.org/10.1175/1520-0469(1963)020<0130:DNF>2.0.CO;2 
Mann, M. E., Steinman, B. A., \& Miller, S. K. (2014). On forced temperature changes, internal variability, and the AMO. Geophysical Research Letters, 41(9), 3211-3219. https://doi.org/10.1002/2014GL059233

Mann, M. E., Steinman, B. A., \& Miller, S. K. (2020). Absence of internal multidecadal and interdecadal oscillations in climate model simulations. Nature Communications, 11(1), 49. https://doi.org/10.1038/s41467-019-13823-w

Matsuura, K., \& Willmott, C. J. (2018a). Terrestrial air temperature: 1900-2017 gridded monthly time series. University of Delaware, Newark, DE Retreived from. Http://Climate. Geog. Udel. Edu/ Climate/Html_pages/Global2017/README. GlobalTsT2017. Html.

Matsuura, K., \& Willmott, C. J. (2018b). Terrestrial precipitation: 1900-2017 gridded monthly time series. Electronic. Department of Geography, University of Delaware, Newark, DE, 19716.

Mérel, P., \& Gammans, M. (2021). Climate Econometrics: Can the Panel Approach Account for Long-Run Adaptation? American Journal of Agricultural Economics, n/a(n/a), 1-32. https://doi.org/10.1111/ajae.12200

Moore, F. C., \& Diaz, D. B. (2015). Temperature Impacts on Economic Growth Warrant Stringent Mitigation Policy. Nature Climate Change.

Moore, Frances C, \& Diaz, D. B. (2015). Temperature impacts on economic growth warrant stringent mitigation policy. Nature Climate Change, 5(2), 127.

Moyer, E. J., Woolley, M. D., Matteson, N. J., Glotter, M. J., \& Weisbach, D. A. (2014). Climate impacts on economic growth as drivers of uncertainty in the social cost of carbon. The Journal of Legal Studies, 43(2), 401-425.

Moyer, E., Woolley, M., Glotter, M., \& Weisbach, D. (2014). Climate Impacts on Economic Growth as Drivers of Uncertainty in the Social Cost of Carbon. Journal of Legal Studies, 43(2), 401-425. 
Newell, R. G., Prest, B. C., \& Sexton, S. E. (2020). The GDP-Temperature Relationship: Implications for Climate Change Damages. Resources for the Future, 71.

Ricke, K., Drouet, L., Caldeira, K., \& Tavoni, M. (2018). Country-level social cost of carbon. Nature Climate Change, 8(10), 895 .

Schlenker, W., \& Roberts, M. J. (2009). Nonlinear temperature effects indicate severe damages to US crop yields under climate change. Proceedings of the National Academy of Sciences, 106(37), 15594-15598.

Smith, J. O. (2007). Mathematics of the Discrete Fourier Transform (DFT): With Audio Applications. Julius Smith.

Taraz, V. (2017). Adaptation to climate change: Historical evidence from the Indian monsoon. Environment and Development Economics, 22(5), 517-545.

Tardif, R., Hakim, G. J., Perkins, W. A., Horlick, K. A., Erb, M. P., Emile-Geay, J., Anderson, D. M., Steig, E. J., \& Noone, D. (2019). Last Millennium Reanalysis with an expanded proxy database and seasonal proxy modeling. Climate of the Past, 15(4).

Taylor, K. E., Stouffer, R. J., \& Meehl, G. A. (2012). An overview of CMIP5 and the experiment design. Bulletin of the American Meteorological Society, 93(4), 485-498.

World Bank. (2021). World Bank Open Data. https://data.worldbank.org/

\section{Acknowledgements}

The authors thank Marshall Burke, Jeffrey Shrader, and Max Auffhammer for comments on the manuscript. Funding for this work was provided by NSF, Award Number 1924378.

\section{Code availability}

The code to replicate the analysis and figures is in:

\section{https://github.com/BerBastien/TempEffectGDP}




\section{Supplementary Figures}

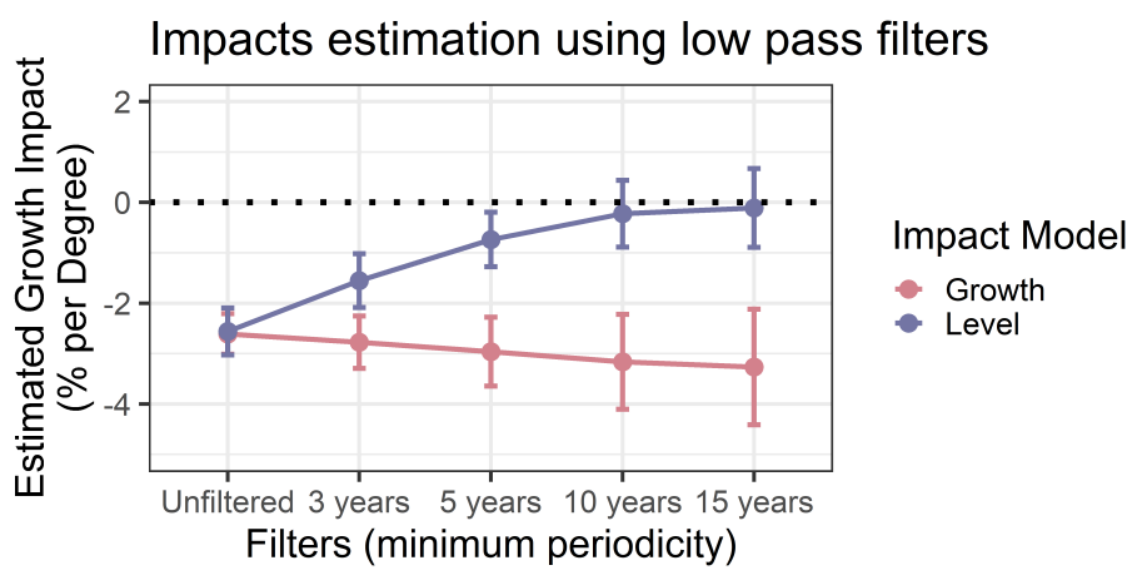

Supplementary Figure 1. Same simulation as described for Figure 2 but adding iid noise $(S D=0.01)$ to the temperature time series. True size effect $=-5 \%$. Note that coefficients in the levels model still trend towards zero at longer filters, but impacts in the growth model intensify slightly due to reduced attenuation bias from filtering out noise in the temperature time series.

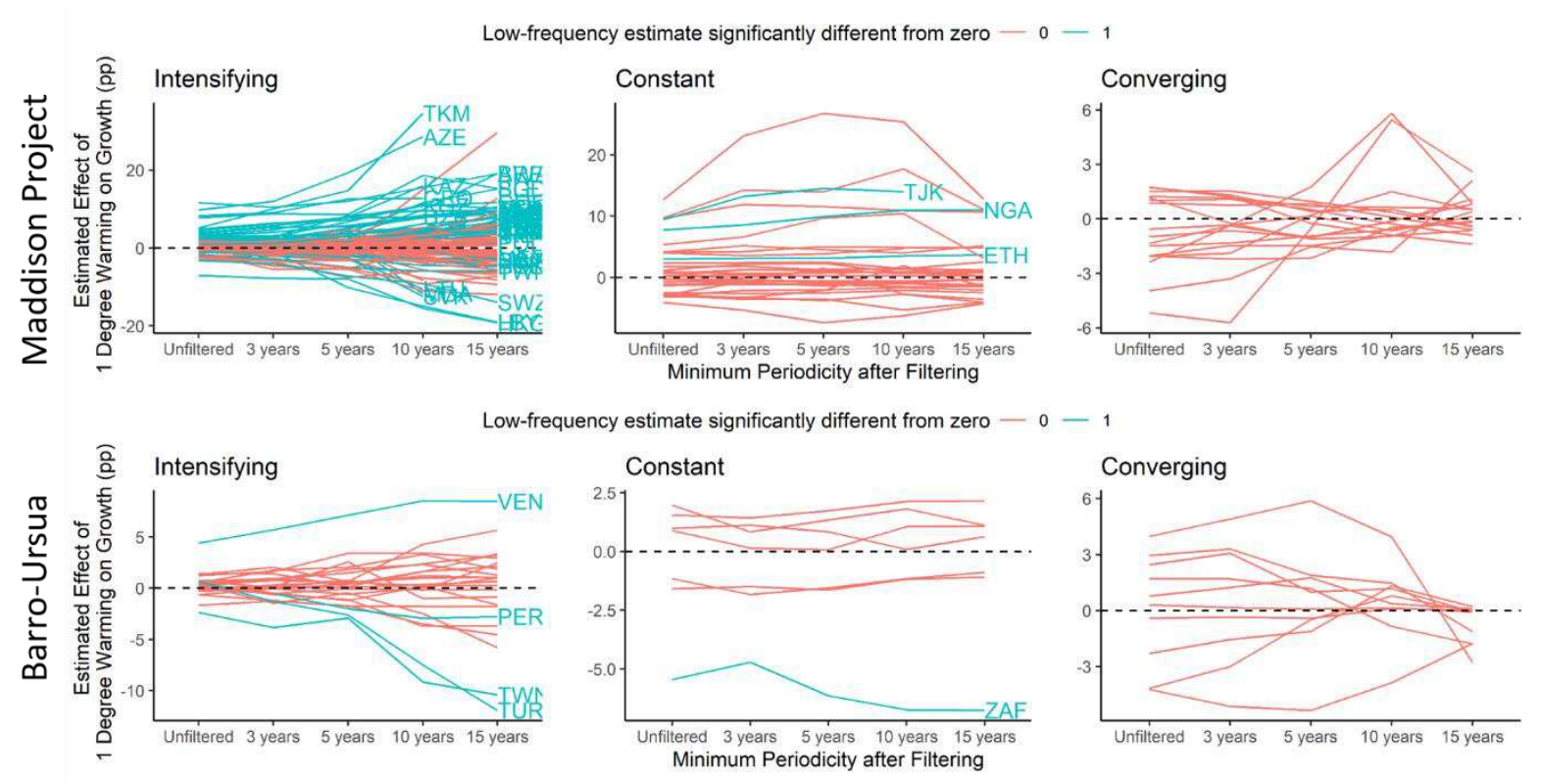

Supplementary Figure 2. Categorization of temperature coefficient estimates for different levels of filtering using alternate economic growth datasets. Top row: Maddison Project economic dataset (Bolt \& van Zanden, 2020), bottom row: Barro-Ursua project economic dataset (R. Barro \& Ursua, 2010). 

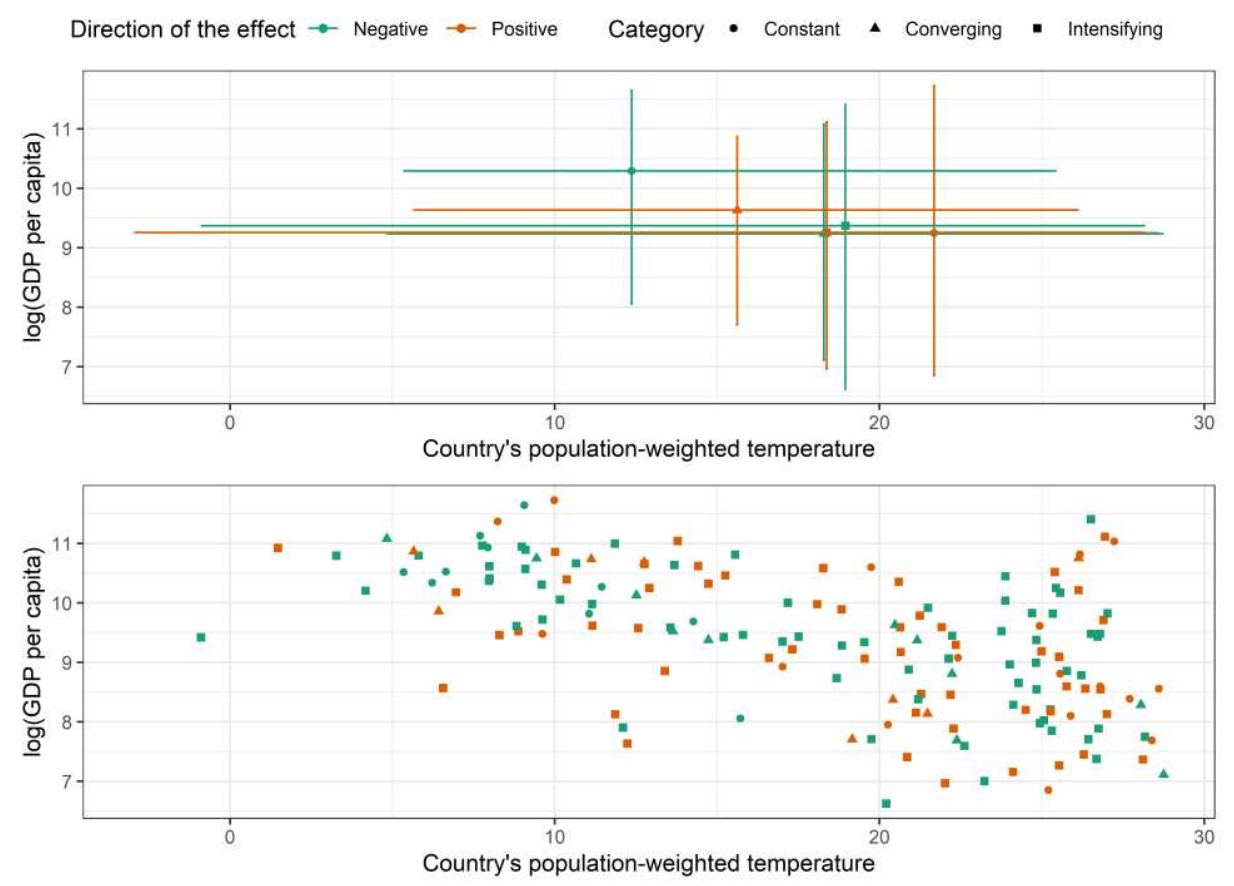

Supplementary Figure 3. Top: The range and mean values of country's mean temperature and log of the GDP per capita for each category of low-frequency effect estimate. Bottom: countries' category, mean temperature and logarithm of the GDP. 